\title{
Correction to: Genetic and genomic resources for improving proso millet (Panicum miliaceum L.): a potential crop for food and nutritional security
}

\author{
Ravikesavan Rajasekaran $^{1}$ (D) . Neethu Francis ${ }^{1}$
}

Published online: 29 September 2020

(c) Archana Sharma Foundation of Calcutta 2020

\section{Correction to: Nucleus \\ https://doi.org/10.1007/s13237-020-00331-2}

Unfortunately, the co-author name Neethu Francis has been incorrectly tagged in the online publication of the article. The correct first name and last name should read as "Neethu" and "Francis" respectively.

The original article has been updated accordingly.

Publisher's Note Springer Nature remains neutral with regard to jurisdictional claims in published maps and institutional affiliations.

The original article can be found online at https://doi.org/10.1007/ s13237-020-00331-2.

Ravikesavan Rajasekaran

chithuragul@gmail.com

1 Department of Millets, Centre for Plant Breeding and Genetics, Tamil Nadu Agricultural University, Coimbatore, Tamil Nadu, India 